\title{
Seasonal controls of weathering processes on the eastern Tibetan Plateau: insights from lithium isotopes
}

\author{
TINGTING MA ${ }^{1}$, SILIANG LI ${ }^{1}$, MARC WEYNELL ${ }^{2}$, JUN \\ ZHONG $^{1}$ AND CONGQIANG LIU ${ }^{1}$ \\ ${ }^{1}$ Institute of Surface-Earth System Science, School of Earth \\ System Science, Tianjin University \\ ${ }^{2}$ Institute of Geological Sciences, Freie Universitat Berlin, \\ Malteser Straße 74-100, 12249 Berlin \\ Presenting Author: tingtingma@tju.edu.cn
}

This study of seasonal lithium (Li) isotopes in the dissolved loads in the catchment of Yalong River on the eastern Tibetan Plateau aims to evaluate the roles of climate and hydrology on silicate weathering. We observe that the isotopic composition of dissolved $\mathrm{Li}\left(\delta^{7} \mathrm{Li}\right)$ exhibits a seasonal variation from $+12.2 \%$ to $+19.5 \%$ in the lower reaches of the Yalong River. The correlations between dissolved $\delta^{7} \mathrm{Li}, \mathrm{Li} / \mathrm{Na}$ ratio, and suspended load concentration suggest that these $\delta^{7} \mathrm{Li}$ variations reflect different proportions of Li uptake by clays during the silicate weathering process. In contrast to the monsoon season, $\mathrm{Li} / \mathrm{Na}$ and $\delta^{7} \mathrm{Li}$ values in non-monsoon season cluster around $\sim 3.2 \times 10^{-3}$ and $+13 \%$. This may be result of shallow groundwaters with short residence times and weak water-rock reaction feeding the river in the limited precipitation season. During the monsoon season with discharge lower than $4000 \mathrm{~m}^{3} / \mathrm{s}$, dissolved $\delta^{7} \mathrm{Li}$ values increase with discharge. Low erosion rate indicates transport-limited weathering because silicate weathering is directly proportional to the supply of material by erosion. In the contrast, monsoon season decrease with discharge higher than $4000 \mathrm{~m}^{3} / \mathrm{s}$, which is summarized as kinetically limited weathering regime. Slow subsurface flow paths with longer transit times would switch to rapid near-surface flow paths with shorter transit times, as discharge increases. Large variation of $\delta^{7} \mathrm{Li}\left(+13.5 \%{ }^{\sim}+19.1 \%\right.$ o $)$ of dissolved load from high-frequency sampling in monsoon season have similar trends with water discharge, which also can be explained by these two weathering regimes. These results suggest that hydrological change is the main reason for the temporal variations of dissolved $\delta^{7} \mathrm{Li}$ in the study basin. Furthermore, positive correlations between physical erosion rate (PER), dissolved Li flux and silicate weathering rates (SWR), which accompanied by increasing discharge. This could support the great importance of hydrological changes (discharge) in PER, dissolved Li fluxes and SWR. Overall, these findings highlight the seasonal sensitivity of silicate weathering process in response to hydrology variability and monsoonal climate in Tibetan Plateau. 